Article

\title{
Determining antecedent pasture state for climate resilient grazing in the pastures of Queensland: An integrated remotely piloted aircraft system and satellite based deep-learning method for estimating time-integrated measures of pasture yield
}

\author{
Jason Barnetson $\left(1,2, *\right.$, Stuart Phinn ${ }^{1}{ }^{1}$ and Peter Scarth ${ }^{\circledR} 1$ \\ 1 Joint Remote Sensing Research Centre, University of Queensland, St Lucia, Brisbane 4072, Queensland, \\ Australia; s.phinn@uq.edu.au (S.P.); p.scarth@uq.edu.au (P.S.) \\ 2 Grazing Land Systems/Remote Sensing Centre, Queensland Department of Environment and Science, \\ Eco-sciences Precinct, Dutton Park, Brisbane 4102, Queensland, Australia; \\ * Correspondence: jason.barnetson@des.qld.gov.au
}

Received: date; Accepted: date; Published: date

check for updates

\begin{abstract}
The aim of this research is to expand recent developments in the mapping of pasture yield with remotely piloted aircraft systems to that of satellite-borne imagery. Up to date, spatially explicit and accurate information of the pasture resource base is needed for improved climate-adapted livestock rangeland grazing. This study developed deep learning predictive models of pasture yield, as total standing dry matter in tonnes per hectare (TSDM $\left(t h a^{-1}\right)$ ), from field measurements and both remotely piloted aircraft systems and satellite imagery. Repeated remotely piloted aircraft system structure measurements derived from structure from motion photogrammetry, provided measures of pasture biomass from many overlapping high-resolution images. Repeated remotely piloted aircraft system measures throughout a growing season, were modelled with persistent photosynthetic pasture responses from various Planet Dove high spatial resolution satellite image-derived vegetation indices. Pasture height modelling as an input to the modelling of yield was assessed against terrestrial laser scanning and reported correlation coefficients $\left(R^{2}\right)$ from 0.3 to 0.8 for both a coastal grassland and inland woodland pasture. Accuracy of the predictive modelling from both the remotely piloted aircraft system and the Planet Dove satellite image estimates of pasture yield ranged from 0.8 to $1.8 \operatorname{TSDM}\left(t h a^{-1}\right)$. These results indicated that the practical application of repeated remotely piloted aircraft system derived measures of pasture yield can, with some limitations, be scaled-up to satellite-borne imagery to provide more temporally and spatially explicit measures of the pasture resource base.
\end{abstract}

Keywords: Remotely piloted aircraft system; structure from motion; photogrammetry; artificial neural networks; deep-learning

\section{Introduction}

Rangelands occupy over $80 \%$ of the state of Queensland Australia and are extensively grazed by cattle, sheep and goats, estimates in excess of 20 million exist [1]. This industry is estimated at over $\$ 5$ billion per-annum [2] net worth. Native pastures account for the majority of the feed-base and the climate is highly variable. The antecedent climatic conditions, including knowledge of the existing pasture growth state, is important in the matching of livestock numbers to the initial and ongoing available pasture resource, requiring continual observation and fine-tuning of herbivore density $[1,3]$.This estimation of stocking rate depends primarily on the assessment of the available and on-going pasture yield and as described by [4] and others [5,6] was traditionally carried out through manual field based sampling and simulation modelling. New techniques utilising both airborne 
remote sensing, including Remotely Piloted Aircraft Systems (RPAS) and space-borne satellite remote sensing are increasingly used to estimate pasture yield. Recent studies by these and other authors have applied both techniques either in other countries or in isolation to one another [4,6,7].

Coupling both RPAS and satellite remote sensing techniques to estimate plant pasture biomass provides a means of a rapid and accurate collection of calibration and validation data, to be then applied across the landscape at the satellite image scale in a more temporal and spatially explicit manner. [4] have developed an RPAS based method to estimate pasture biomass at the field site scale for use in further scaling to satellite remotely sensed imagery. Techniques developed by [7] have demonstrated scaling RPAS derived imagery up to the satellite image, in a method that aims to estimate plant pasture production as a product of Absorbed Photo-synthetically Active Radiation (APAR). This is derived from both satellite measured photosynthetic vegetation and light use efficiency (LUE) modelling. Eco-physiological modelling of plant pasture biomass is well established in the literature [8-14] and provides a robust method through converting photo-synthetically active radiative energy into plant biomass on the efficiency of light use. Plant pasture production is considered a product of both Absorbed PAR (APAR) and LUE [15] in [7]. As [7] further states APAR can be easily estimated from remotely sensed data and provides a potential metric, along with correctly calibrated LUE modelling, for the estimation of plant pasture yield at the satellite imagery scale. [7] also states that a significant challenge exists in parameterising LUE as a function of environmental variables, namely soil moisture deficits and temperature extremes. Although robust spatially explicit LUE modeling parameters for all climates, pastures, and soil types don't exist across most landscapes at a pasture management scale, including the rangelands of Queensland, the use of satellite-derived measures of photosynthetic active pasture still serve as means of estimating pasture production. Accumulated or persistence of photo-synthetically active pasture can be measured at the satellite scale through space and time, providing a means of estimating net primary pasture production, that can be compared and further modelled with both field measurements and RPAS estimates of pasture yield.

Optical satellite imagery is considered by some to be most useful for the estimation of pasture yield [6], namely due to its high spatial resolution and regular daily repeat intervals. Conventional optical satellite sensor platforms include the MODIS and Landsat systems and more recently the European Space Agency's Sentinel 2 constellation. The spatial resolution of these sensors ranges from 10 to 500 metres and temporal resolutions of daily to every fourteen days. The spectral resolutions range from the visible to the short-wave infrared. Each of these platforms has benefits to remotely sensing plant pastures, namely their sensitivity to plant physiological processes, primarily photosynthesis, and their high spatial resolution and repeat cycle, all-important in measuring and monitoring changes in plant pasture growth. Various studies have reported good results from these platforms including $[6,16-$ 18] that primarily utilised Sentinel 2 imagery. However, each of these platforms either lacks one or other necessary components, primarily temporal revisit interval (daily) and spatial resolution $(<5 \mathrm{~m})$ needed to adequately measure changes in plant pasture growth at the intensive livestock management spatial scale. Temporal revisit time is a critical component to both capture change in plant pasture yield, as a result of growth and livestock utilisation, for timely pasture management, as well as providing cloud-free imagery, which is often a significant limitation of optical sensors that are masked by cloud. A further issue is the association of plant pasture growth with precipitation and cloud, further compounding the need for cloud-free imagery during the growth phase of the pasture. [6] and others have noted that this is a significant limitation of these platforms, particularly in temperate and tropical environments. The development of the commercial Planet Dove constellation [19] of hundreds of small high-spatial-resolution $(<5 \mathrm{~m})$ satellites providing daily repeat visit intervals, have potentially filled this gap. As it provides regular repeat imagery, the occurrence of cloud/part-cloud free imagery is higher than the other platforms at an improved high-spatial resolution $(<5 \mathrm{~m})$. Although not freely available and still in sensor radiometric improvement and development, the platform is however well suited to commercial livestock pasture management. 
Methods used to map and monitor plant pasture biomass from both RPAS and satellite imagery have traditionally utilised regression-based algorithms, including $[18,20]$. New techniques involving the use of machine learning techniques have recently been employed in a number of studies [6, 21]. [6] in their study of a dairy pasture system in Tasmania Australia employed a deep-learning Artificial Neural Network (ANN) method, to explore and extract complex and high dimensional information from Sentinel 2 satellite data. These algorithms, although considered complex, are in essence based on foundation statistical theory, however with the development of fast and parallel compute processes, able to handle and manage networks of large and complex computations. Compute facilities and consumer-available computing resources are becoming cost-effective and accessible to both researchers and practitioners. These methods rely on large amounts of training data to represent complex systems [22] including natural systems such as plant pasture growth and its associated yield. These systems are both spatially complex across landscapes, as well as through time from the frequent phenological change of growth and decay. This presents a significant challenge to the adoption of such systems, whereby efficient and cost-effective field calibration data is needed. In comparison to manual techniques of pasture yield sampling, the use of RPAS technologies has the potential to rapidly acquire high-resolution spatial information, in the volumes required to train such complex machine learning algorithms.

The aim of this study was to first develop, employ and test the accuracy of RPAS technology to acquire sub-metre high-resolution imagery, for the development of a plant pasture yield model, across both grassland and woodland pastures, at repeated intervals throughout a period of pasture growth. Utilising techniques developed previously by [4], the study employed photogrammetric structure from motion methods to map pasture height, and with coincidental repeated manual pasture yield sampling, further developed a pasture height machine learning model of pasture yield at monthly intervals throughout the growing season. Secondly, reporting on the accuracy of the RPAS pasture yield modelling, the study further tested the ability to utilise these pasture yield estimates at each growth stage, to both train and evaluate a satellite-derived deep-learning ANN model of pasture yield. Planet Dove satellite image data measures of persistent photosynthetic plant pasture response from the beginning of the growing season up until the RPAS modelled estimate of yield, were regressed with each yield estimate and the ANN model calibrated and evaluated.

\section{Materials and Methods}

\subsection{Study area and data acquisition}

Two locations across the region of South East Queensland in Eastern Australia were chosen for the repeated collection of both RPAS imagery and manual plant pasture yield sampling. Both locations were chosen to provide ready access from the city of Brisbane at monthly intervals. The first location, the Queensland University of Technology (QUT) Samford Ecological Research Facility (SERF), was chosen as a representative sub-tropical mixed native and introduced grassland pasture, common throughout the coastal zone of Queensland. Located on fertile alluvial soils in close proximity $(<20 \mathrm{klm})$ to the coastline (see figure 1) and with an annual average rainfall of $1100 \mathrm{~mm}$ [23], pasture yield was considered to be on average in excess of 10 total standing dry matter tonnes per hectare (TSDM $\left.\left(t h a^{-1}\right)\right)$ at its peak growth stage. The second field site, located on a private cattle grazing property close to the township of Esk, approximately $60 \mathrm{~km}$ from the city of Brisbane (see figure 1), is located further from the coastline $(\sim 60 \mathrm{~km})$ and considered less affected by any land-sea climate interactions and more typical of in-land pastures, soils are more skeletal and annual average rainfall lower at $973 \mathrm{~mm}$ [23], average yield was expected in the range of 5 to 10 TSDM (tha $\left.{ }^{-1}\right)$. Both field sites climate patterns are warm and moist summers and cool and dry winters in a sub-tropical wet / dry cycle. Rainfall typically increases from the month of November, on average peaks in February / March and decreases into a dry period from the month of May on-wards to the end of October. The total monthly rainfall from the beginning of the growing season to peak growth, for each field site, is 


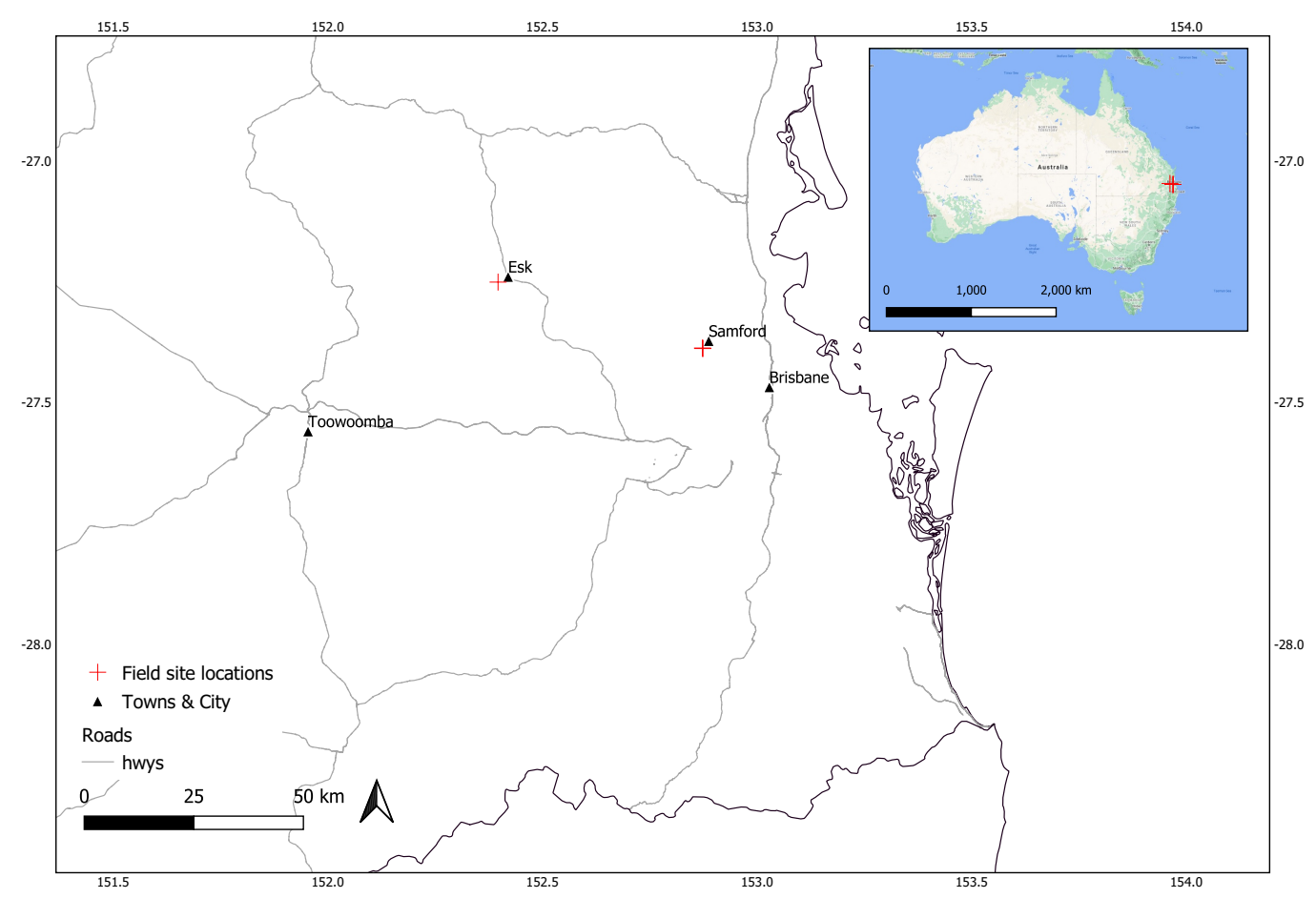

Figure 1. Location of study area in relation to South East Queensland and Australia.

illustrated in figure 2 from automated rain gauge systems installed at both locations. Average daily temperatures follow a similar pattern and pasture growth follows. Pasture composition and further soil and pasture site resource details are described in table 1 along with the timing of each field site RPAS capture and sampling campaign. At each of the two locations, two separate monitoring plots were established, each $50 \times 50$ metres in size, located nearby one another in similar representative locations of the surrounding pasture community.

Table 1. Field site characteristics.

\begin{tabular}{|c|c|c|}
\hline & Esk & Samford \\
\hline Pasture types & $\begin{array}{l}\text { Sub-Tropical Woodland } \\
\text { (STW) }\end{array}$ & Sub-Tropical Grassland (STG) \\
\hline $\begin{array}{l}\text { Common pasture } \\
\text { species }\end{array}$ & $\begin{array}{l}\text { Heteropogen contortus, Imperata cylindrica } \\
\text { Melinis repens, Chloris gayana and Chrysopogon sp's. }\end{array}$ & $\begin{array}{l}\text { Paspalum mandiocanum, Chloris gayana \& } \\
\text { Imperata cylindrica }\end{array}$ \\
\hline Associated vegetation & $\begin{array}{l}\text { Eucalyptus maculata } \mathcal{E} \\
\text { E.crebra }\end{array}$ & $\begin{array}{l}\text { Various forbs and ephemeral } \\
\text { grasses }\end{array}$ \\
\hline Soil types & Shallow red earthy loam & Gleyed soils in local alluvium \\
\hline No. of field plots & 2 & 2 \\
\hline Sampling dates & $\begin{array}{lr}1-12-2020, & 16-12-2020, \\
28-01-2021, & 22-02-2021, \\
16-03-2021, & 29-03-2021\end{array}$ & $\begin{array}{l}5-11-2020, \quad 3-12-2020,5-01-2021 \\
9-02-2021,26-02-2021,08-03-2021\end{array}$ \\
\hline
\end{tabular}

\subsection{RPAS, satellite and field data}

\subsubsection{RPAS data capture}

RPAS imagery was collected at each field site visit following the establishment of ground control targets, sampling transects, and quadrats but prior to destructive field sampling. Ground 


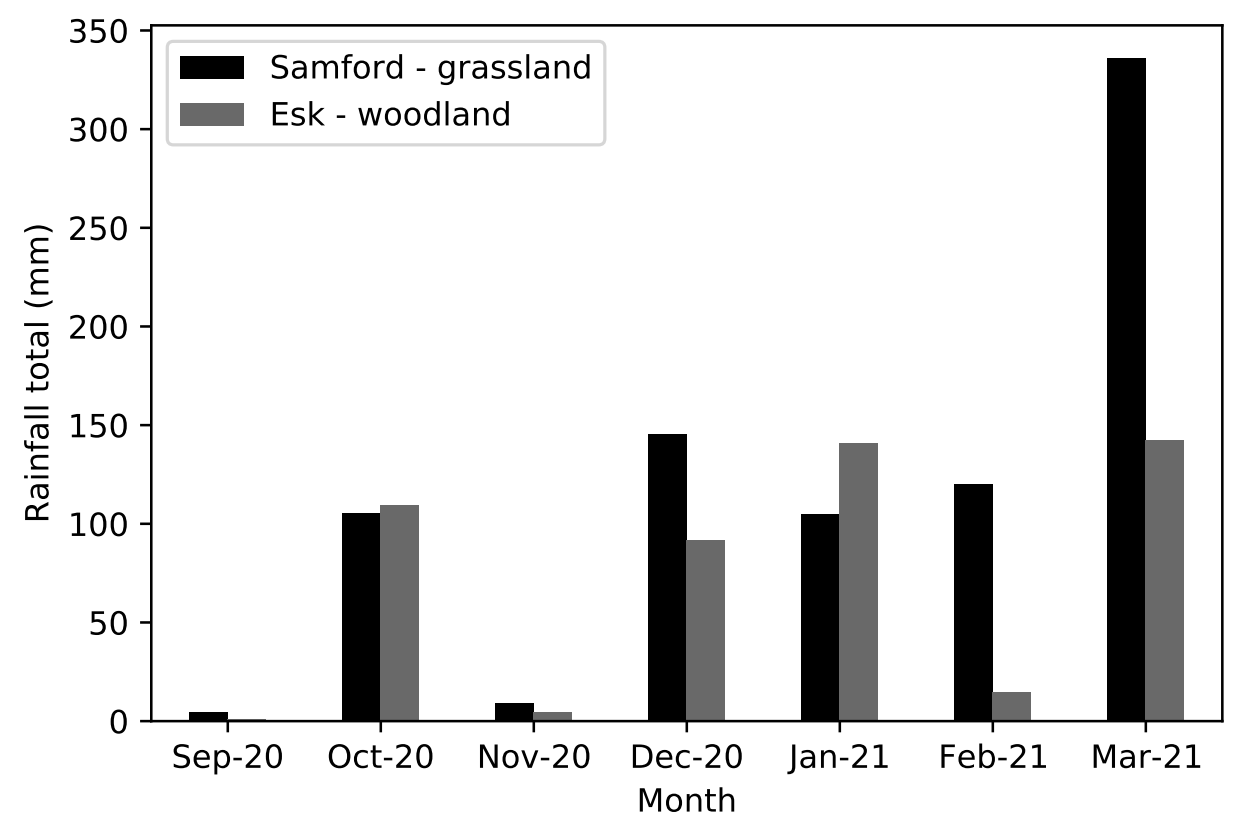

Figure 2. Monthly rainfall totals for both field sites from September 2020 to March 2021.

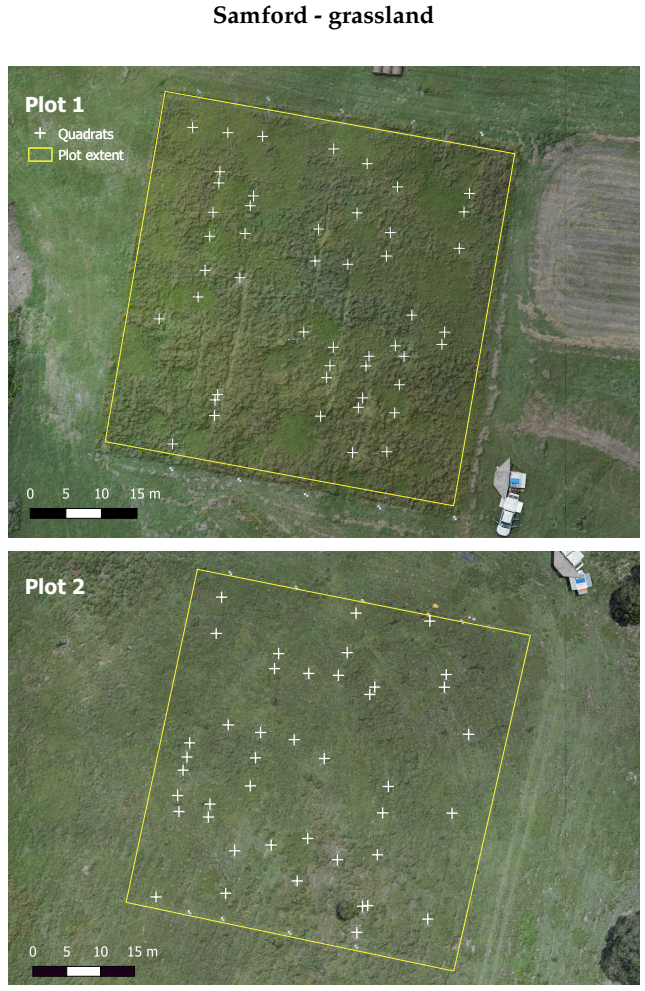

(a)
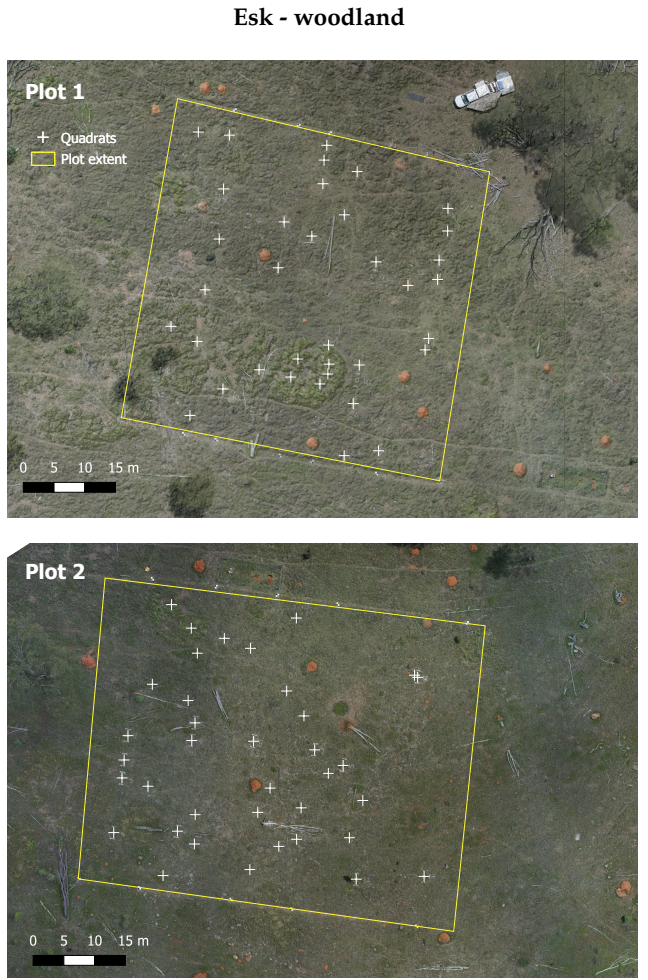

(b)

Figure 3. Illustration of the grassland field site plot one and two within the Samford Ecological Research Station (a) and the woodland field site plots (b) near the township of Esk. White markers illustrate the locations of the quadrats sampled during the growing season. 
control consisted of a minimum of five targets placed at each corner and the centre of each field plot. Differential GNSS positions were established through the survey of each target with a GNSS rover/base station system. The UgCS mission planning software version $2.0^{\mathrm{TM}}$ was used to program each autonomous flight. The average flight mission parameters and the equipment used for each photogrammetric mission are detailed in Table 2. All flights were conducted between the hours of 10:00 to 14:00 hours local time to reduce shadowing and each campaign was flown in clear to minimal cloud.

Image processing of the DSLR RGB images was performed with the Pix4D commercial software [24]. Applying the same Structure from Motion (SfM) methods in Pix4D with the RGB images and GCP targets as [4], a Dense Point Cloud (DPC) was generated for each campaign. The processing parameters and resources are presented in Table 2.

Table 2. RPAS flight mission \& processing parameters.

\begin{tabular}{ll}
\hline Equipment & \\
\hline Aircraft & DJI M600Pro ${ }^{\mathrm{TM}}$ \\
Gimbal & DJI Ronin-MX ${ }^{\mathrm{TM}}$ \\
\hline Camera \& Photogrammetry parameters & \\
\hline Camera & Sony Alpha 7R II ${ }^{\mathrm{TM}}$ \\
Trigger & intelliG ${ }^{\mathrm{TM}}$ wifi sync trigger \\
Lens & $24 \mathrm{~mm}$; aperture priority \\
Sensor & $42 \mathrm{mpx} ; 3 \mathrm{~mm}$ full frame; RGB \\
Image format & JPEG file format; $15 \mathrm{MB}$ per image; bit depth RGB (14) \\
Flying height & $\sim 50 \mathrm{~m}$ \\
Image size & $9-10 \mathrm{~mm}$ ground sampling; $75 \times 50 \mathrm{~m}$ footprints \\
Ground speed & $1.5-2 \mathrm{~m} / \mathrm{s}$ \\
Image count & $\sim 150$ per site at nadir \\
Image forward \& side overlap & $90 \%$ \\
Flight time & $20-30 \mathrm{~min}$ \\
Flight pattern & Grid in north/south alignment; stop and turn at ends \\
\hline Pix4D SfM photogrammetry processing parameters & \\
\hline Keypoints image scale & Full \\
Point cloud densification & Original image size \\
Minimum no. of matches & 3 \\
Point density & Optimal \\
Resolution & $1 \times$ GSD \\
\hline \hline
\end{tabular}

\subsubsection{Planet Dove satellite image data imagery}

The Planet Dove constellation is made up of multiple launches of groups of individual satellites, each a small $10 \mathrm{~cm} \times 10 \mathrm{~cm} \times 30 \mathrm{~cm}$ Cube-sat [25]. Consisting of over 200 individual sun and non-sun synchronous Cube-sats orbiting the earth and providing daily coverage. The Planet Dove satellite image surface reflectance data were acquired for each daily capture from the beginning of the pasture growth cycle, typically the beginning of the month of October up until the date of the field visit, and that was identified cloud-free by the Planet Dove cloud filtering process. Each image was then downloaded from the Planet Dove website under their education and research access program. Each 16-bit ortho-rectified image has three spectral bands in the visible and one in the Near Infra-Red spectrum, each with a three metre pixel resolution. Sensor radiance is processed to top of atmosphere reflectance and then atmospherically corrected to bottom of atmosphere reflectance from a series of MODIS satellite derived atmospheric models [19]. Further manual filtering of each field site downloaded image collection was performed to remove commission errors from the automated cloud filtered images. Table 3 summarises each field site location's Planet Dove satellite image data collection. 
Table 3. Planet Dove satellite image data parameters and collection details.

\begin{tabular}{lll}
\hline Specifications & \\
\hline Product & PSScene4Band ${ }^{\mathrm{TM}}$ - analytic \\
Corrections & Surface reflectance \\
\hline Ground sample resolution & $3-3.5 \mathrm{~m}$ \\
Bands & Blue $(450-515 \mathrm{~nm})$, Green $(500-590 \mathrm{~nm})$, Red (590-670 nm), NIR (780-860 nm) \\
Camera dynamic range & 12-bit & Woodland \\
\hline Images per month & Grassland & 7 \\
\hline October & 2 & 9 \\
November & 10 & 3 \\
December & 3 & 4 \\
January & 1 & 3 \\
February & 2 & 4 \\
March & 2 & 30 \\
\hline Totals & 20 & \\
\hline
\end{tabular}

\subsubsection{Destructive pasture sampling}

Destructive harvesting of both live and dead plant pasture material was carried out at monthly intervals throughout the growing season. A total of 12 quadrats were established per visit. Quadrats were stratified across the plot by means of random placement along 10 evenly separated linear transects that were placed in a north/south orientation at five metres apart. Each quadrat was only sampled once throughout the growth period. Each quadrat consisted of a 0.5 metre wide $\times 2$ metre long outer quadrat, marked at each corner by way of a one metre tall post and reflective $50 \times 50 \mathrm{~mm}$ cube shaped end cap. Sides of the quadrat were delineated with spray paint. A smaller $0.5 \times 0.5$ metre steel framed inner quadrat was placed in the centre of the larger outer quadrat. The inner quadrat was sampled first by way of electric shears, pastures were removed and placed in individual paper bags. The outer quadrat pastures were then removed by way of a slashing petrol driven mower, clippings were collected in a catcher and transferred to individual calico bags. All samples were then placed in a drying oven for a minimum of 72 hours at 65 degrees Celsius and weighed to determine overall TSDM.

\subsection{Methods}

\subsubsection{RPAS pasture height modelling}

The photogrammetric processing of RPAS overlapping imagery produced a dense point cloud for each field plot. A total of 12 point clouds were produced, each consisting of an average 10 to 30 thousand points. Each point cloud was processed from surface elevation to pasture height utilising the Point Data Abstraction Library (PDAL) [26] implementation of [27]'s progressive morphological filter to classify each point into a ground or non-ground class. The PDAL Height Above Ground Nearest Neighbour (HAG-NN) filter was then used to calculate the height of each non-ground point as the difference in elevation between each non-ground point and its nearest ground point. Default parameters were used in both processes. Each sampling quadrat corner marker was next manually located in each processed cloud from their reflective end cap targets and the extent of each quadrat digitised. A series of height metrics were calculated for each quadrat including the spatial average minimum, maximum, mean, and median pasture height across each quadrat. These were attributed to each sample quadrat number and visit and used as inputs for further pasture yield modelling, and the following validation process.

Validation of each quadrat height metric involved a comparison with the same metrics derived from a terrestrial laser scanner point cloud acquired immediately after each photogrammetric RPAS capture. A Riegl VZ-400i Terrestrial Laser Scanner was used to collect individual horizontal scans across each field site plot, at on average a 15-metre distance from one another, spread across each field plot in a 
grid pattern. Scan pattern was set at 30 milli-degrees and measurement speed at a pulse repetition rate of $1200 \mathrm{kHz}$ to provide sufficient detail in an efficient time of one minute per scan. A total of 20 scans per plot were collected. Reflective $50 \mathrm{~mm}$ diameter survey-grade cylindrical targets were established atop of surveys posts at the corners of each field plot, and a high-resolution 'target' scan was carried out to aid in the scan registration process. Reigl RiScan Pro software was used to post process all of the scans. Registration of each scan was carried out using the 'Automatic registration 2' process with the 'outdoor non-urban' option selected. Further refinement of each scan registration and linkage of the GNSS surveyed ground control targets with each associated reflector scan was conducted through the 'multi-station 2' process, with the 'points to planes' option selected. A single LAS file of each point cloud was created and exported from RiScan. The same steps as the photogrammetric pasture height point cloud processing were used to derive a pasture height point cloud from the exported TLS LAS file, along with each individual quadrat height metric. Each quadrat photogrammetric and TLS height metric were then compared with one another in a least squares linear regression and the errors reported.

\subsubsection{RPAS pasture yield modelling}

Pasture yield was next predicted from the quadrat scale RPAS derived pasture height metrics of maximum, mean and median height and their associated field measurements of pasture yield. Implementation of an Artificial Neural Network (ANN) deep-learning machine learning algorithm involved the use of the TensorFlow software framework [28], in particular the python software language Keras ANN module within the framework. The Keras module provides a simple high-level implementation of complex machine learning algorithms in a train then test approach. The multi-layer perceptron (MLP) ANN was used to estimate pasture yield from the RPAS derived pasture metrics with the yield measurements used for training and testing. The model structure was similar to the model used by [6], in their ANN modelling of pasture yield in a dairy pasture, in that it consisted of two hidden layers (64 nodes each) and one output layer. Dropout and kernel constraints were added to assist in preventing over training of the model. Activation of the model used the rectified linear unit (ReLU) function and optimisation with the Adam optimiser at a rate of 0.001 . Loss functions used the huber loss between the true and predicted values at a delta of 0.1 , and the evaluated metrics during training and testing were the mean absolute and mean square errors. A randomised split of $70 / 30$ train then test was conducted and a maximum of 1000 epochs to train the model was used, however, over-fitting of the model was managed through stopping the model training when the loss function started to increase. Normalisation of the input data was carried out prior to training through subtraction of the mean and dividing by the standard deviation. To ensure an adequate number of samples for training and testing of the model, both grassland and woodland quadrat samples were combined and the results reported the combined pastures.

Following the development of the RPAS pasture yield model, further predictions of pasture yield across each RPAS pasture height point cloud were estimated. This involved, first the calculation of each pasture height metric across the entire RPAS pasture height point cloud. In order to calculate these metrics a moving window was employed across a pasture height image, derived from each point cloud, and the average of each pasture height metric from the windows $3 \times 3$ pixel assigned to the windows central pixel. Pasture height metric images of maximum, mean and median were generated for each RPAS capture and then used to predict pasture yield of each image pixel using the developed ANN yield model.

In order to further predict pasture yield at the Planet Dove satellite image scale, each RPAS estimate of pasture yield image was re-scaled to the Planet Dove satellite image data pixel scale of three metres and transformed to the same geographic projection. 


\subsubsection{Time-series measure of persistent green pasture}

A measure of persistent photosynthetic pasture was next calculated from a number of Planet Dove satellite image data time-series vegetation indices, as an indicative feature measure of pasture yield, matched with the RPAS re-scaled pasture yield labels, to further predict pasture yield at the Planet Dove satellite image scale. A time-series from the beginning of the defined growing period up until the final field site visit for each pixel, of each image band, was extracted from the downloaded Planet Dove satellite image data surface reflectance image collection. A number of vegetation indices were calculated including: MSAVI, NDVI, RDVI and TVI, these were chosen for their use in other remote sensing vegetation studies and in particular for their performance in both distinguishing vegetation from background soils, reducing the effects of over saturation in high biomass vegetation and in determining leaf area index, a common plant physiological parameter used in several studies to estimate plant growth. Table 4 details each index, its calculation equation and literature source as modified from [29].

Table 4. Chosen vegetation indices.

\begin{tabular}{|c|c|c|}
\hline Index & Equation & Source \\
\hline $\begin{array}{l}\text { Modified Soil-Adjusted Vegetation Index } \\
\text { (MSAVI) }\end{array}$ & $0.5\left[2 N I R+1-\sqrt{(2 N I R+1)^{2}-8(N I R-R e d)}\right]$ & [30] \\
\hline Modified Triangular Vegetation Index (MTVI) & $1.5[1.2($ NIR - Green $)-2.5($ Red - Green $)]$ & [30] \\
\hline $\begin{array}{l}\text { Normalised Difference Vegetation Index } \\
\text { (NDVI) }\end{array}$ & $\begin{array}{l}\sqrt{(2 N I R+1)^{2}-(6 N I R-5 \sqrt{R e d})-0.5} \\
\frac{N I R-R e d}{N I R+R e d}\end{array}$ & [31] \\
\hline $\begin{array}{l}\text { Re-normalised Difference Vegetation Index } \\
\text { (RDVI) }\end{array}$ & $\frac{N I R-R e d}{\sqrt{N I R+R e d}}$ & [32] \\
\hline Transformed Vegetative Index (TVI) & $\sqrt{\frac{N I R-R e d}{N I R+R e d}+0.5}$ & \\
\hline
\end{tabular}

Time-series analysis of each vegetation index involved a number of steps including; interpolation of missing values, filtering of anomalous errors, determining the growth period and calculating a measure of pasture persistence.

Missing values

The interpolation of missing values in the time-series, as a result of cloud obscuring the target area, involved the use of a linear interpolation from one valid observation to the next at daily intervals. Filtering

The interpolated time-series was next smoothed to remove anomalous high and low values, likely the result of atmospheric scattered effects from the thin cloud, dust, and smoke, that had not been removed in the atmospheric correction of the Planet Dove satellite image data surface reflectance product. Smoothing involved the fitting of a uni-variate spline to the data using the same procedure as [33], to remove anomalous values whilst still preserving the temporal trend of the time-series.

Growth period

The next stage involved calculating the derivative of the fitted spline function to define the cross-over or break-points in the time-series, both the peaks and troughs were defined in this manner, the lowest trough point in terms of vegetation index response was defined as the pasture growth start point in the time-series. The pasture growth end point for each field site was determined as the date of final field visit of each field plot.

Persistence measure

The persistence of each vegetation index time-series was next calculated from the defined start to end 
points. This involved the calculation of the Pearson's correlation between the time-series and a shift of the time-series by 10 days, the length of this lag period was chosen to best reduce the effects of short-lived ephemeral forbs and grasses inflating the measure of persistence.

\subsubsection{Planet Dove satellite image data based pasture yield modelling}

Planet Dove satellite image data pasture yield modelling was next carried out from the derived pasture persistence features and the RPAS yield labels. In order to first understand the utility of using both of these features and labels to accurately predict yield, a simple linear least-squares regression of both was carried out. A stratification of the regression was manually carried out to define each feature/label pair of pixels into two distinct categories. The first being those pixels with a high measure of photosynthetic persistence (class 1 ) and the second with a range of both moderate and low persistence (class 2). Both classes of pixels were further interrogated across each field site and confirmed from the RPAS high-resolution imagery to be of either a taller $(>10 \mathrm{~cm})$ tussock grass or forbs form, or short $(<10 \mathrm{~cm})$ broad-leaved prostrate grass or creeping forb form. Each pasture form was modelled separately, utilising the same ANN modelling procedure as the RPAS pasture yield modelling, and the results reported.

\section{Results}

\subsection{RPAS pasture height}

The validation of each quadrat photogrammetric derived height metric measurement is illustrated in figure 4. The average minimum quadrat height showed the strongest agreement between the terrestrial laser scan and the RPAS photogrammetric height models for the grassland pasture, followed by the mean. The maximum height demonstrated the least agreement for the woodland pasture. Agreement within the grassland and woodland pasture height metrics followed the same pattern. 


\section{Grassland}

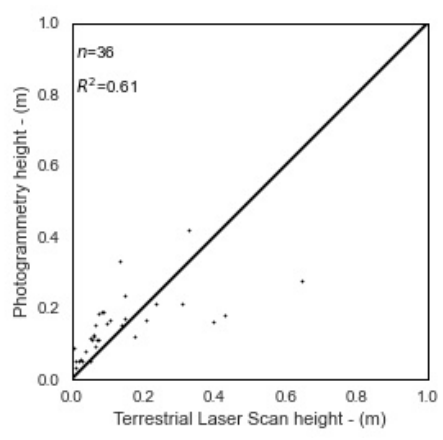

(a)

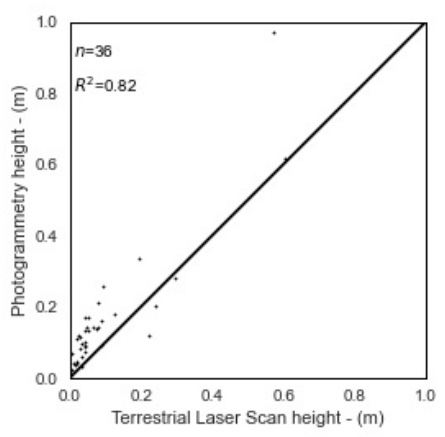

(c)

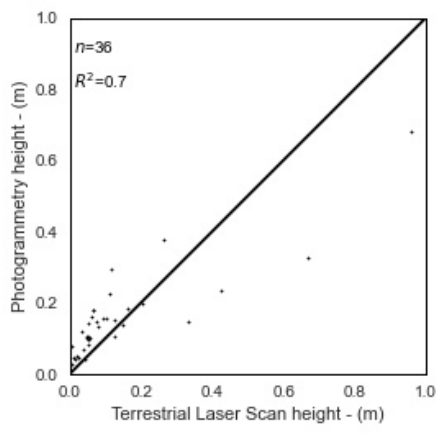

(e)

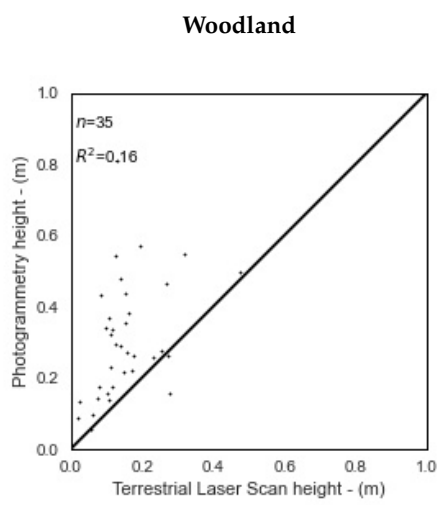

(b)

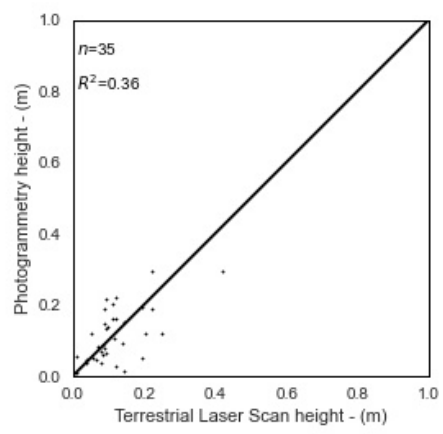

(d)

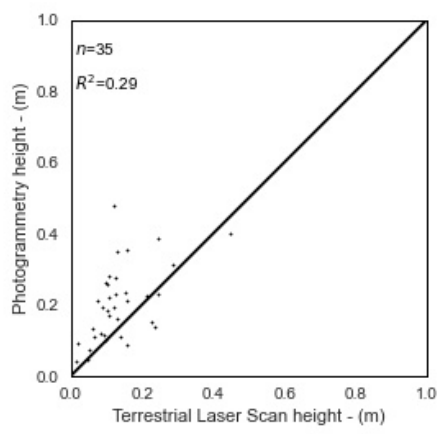

(f)

Figure 4. Least squares linear relationship between terrestrial laser scanner measured height and RPAS photogrammetric estimated height for the grassland and woodland communities. Average maximum quadrat height $(\mathrm{a} \& \mathrm{~b})$, average minimum quadrat height $(c \& d)$ and average mean quadrat height (e $\& \mathrm{f})$. 


\subsection{RPAS height estimates for estimation of pasture yield}

The relationship of the pasture yield predictions derived from the RPAS height modelling and associated field measurements of pasture yield is illustrated in figure 5 for the combined grassland and woodland ANN modelling, including both the calibration of the modelling and its assessment. Error assessment of the modelling reveals a mean absolute error of 0.8 TSDM $\left(t h a^{-1}\right)$ in the models calibration and 1.4 TSDM $\left(t h a^{-1}\right)$ in its assessment. The range was 0.5 to 9 TSDM $\left(t h a^{-1}\right)$. Figure 6 further illustrates the RPAS predicted yield at the Planet Dove satellite image data pixel scale for three chosen field visit dates throughout the growing period, along with the associated RPAS high-resolution RGB and pasture height modelled imagery. Pasture yield can be seen increasing throughout the growing period, this is most prominent in the grassland pasture. 


\section{Calibration}

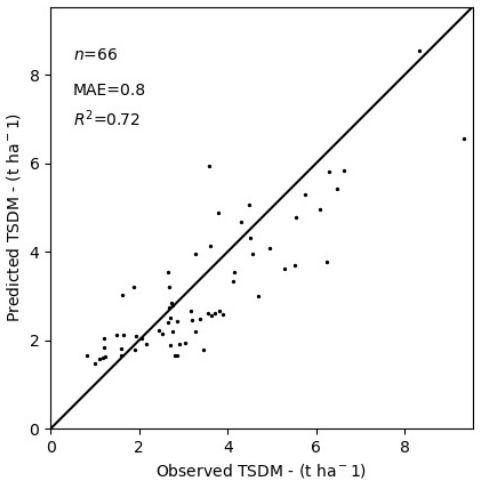

(a)

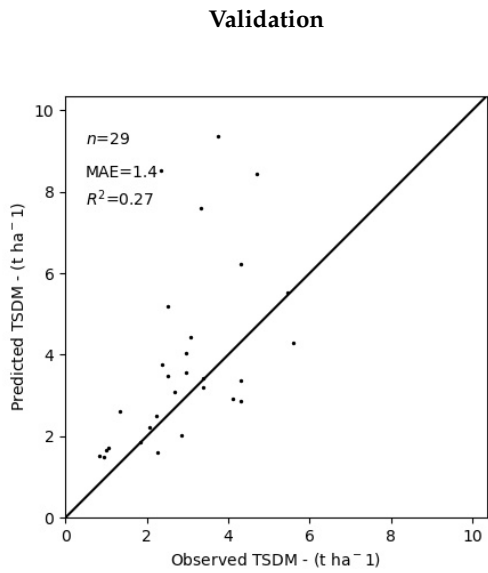

(b)

Figure 5. Least squares linear relationship between field measured biomass and RPAS predicted biomass for both the model training (a) and testing (b).

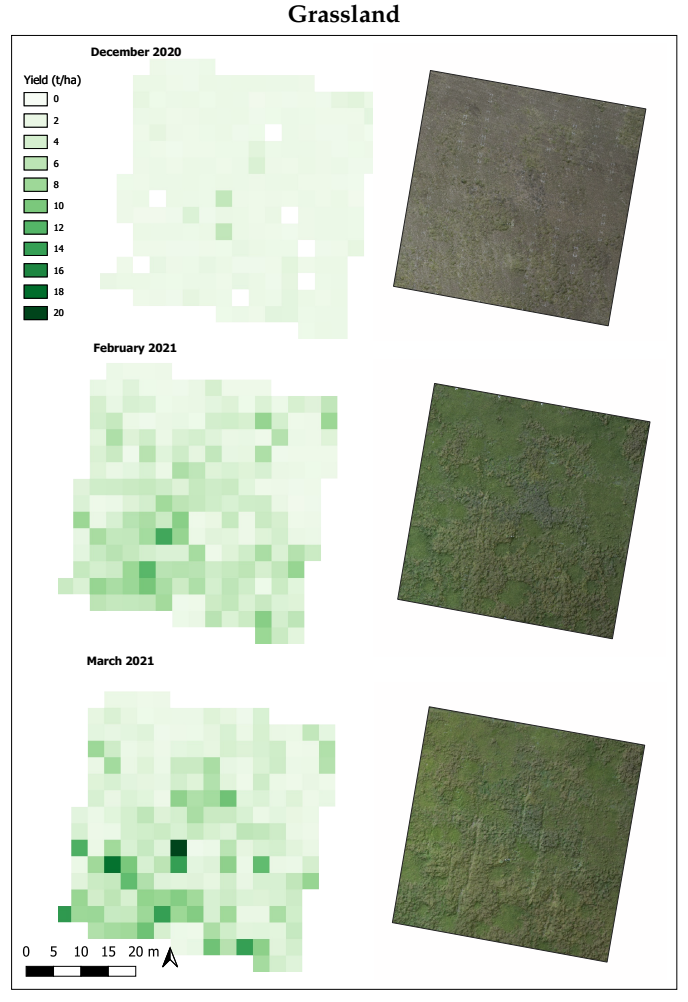

(a)

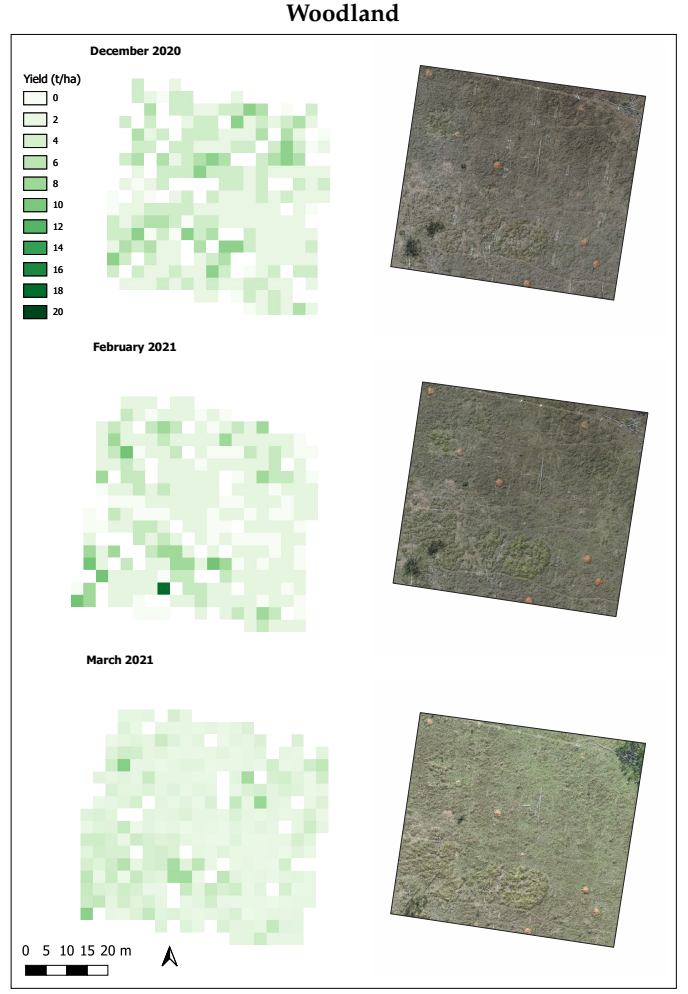

(b)

Figure 6. Example predicted pasture yield maps of both the grassland and woodland field plots ( $\mathrm{a} b$ ). The left hand sides of each plate are the re-scaled RPAS-based model predictions of yield and the right hand side are the RPAS derived high-resolution images overlaid onto the associated pasture height models from the December, February \& March RPAS captures. 


\subsection{Satellite estimation of pasture yield}

\subsubsection{Satellite measures of pasture persistence and correlation with RPAS predicted yield}

Example Planet Dove satellite image data time-series plots of both grassland and woodland field plots, average photosynthetic pasture response are first illustrated in figure 7. A measure of photosynthetic persistence for the NDVI vegetation indices, from each pixel time-series is next plotted against the associated RPAS modelled pasture yield pixel in figure 8, the stratification of each plot into tall and short pasture classes is shown along with the result of each stratification class least-squares linear regression. The tall pasture class is shown to have the weakest relationship for both the grassland and woodland pastures. A further map of one of each field pasture plot illustrates the tall / short pasture class stratification.

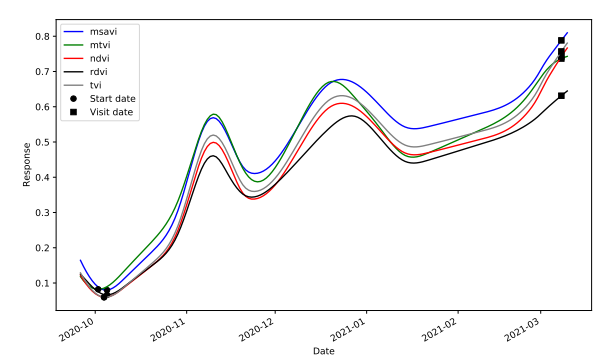

(a)

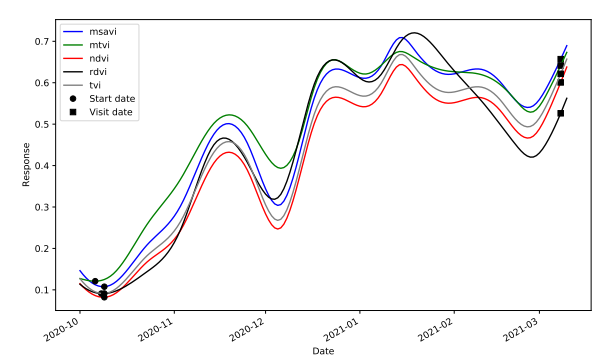

(b)

Figure 7. Planet Dove satellite image data time-series plots of the average vegetation index response across one of the grassland (a) and woodland (b) field site plots, the start and end points of the time-series measure of pasture persistence are also indicated in each plot.

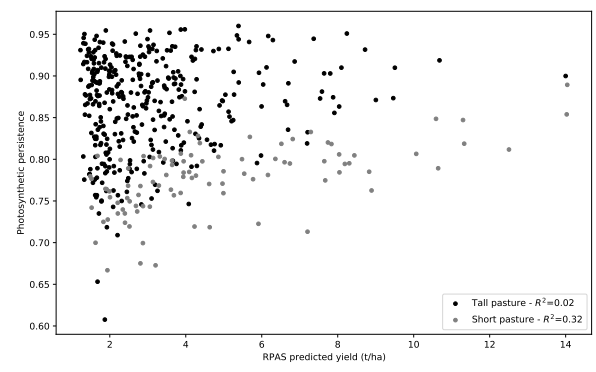

(a)

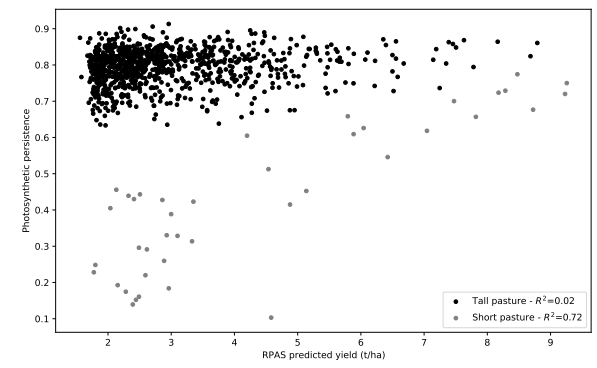

(b)

Figure 8. Relationship between the RPAS estimated yield and Planet Dove satellite image data persistent photosynthetic pasture for both the grassland (a) and woodland (b) field plots. Dark points indicate the tall pasture form and the grey points the short form. 


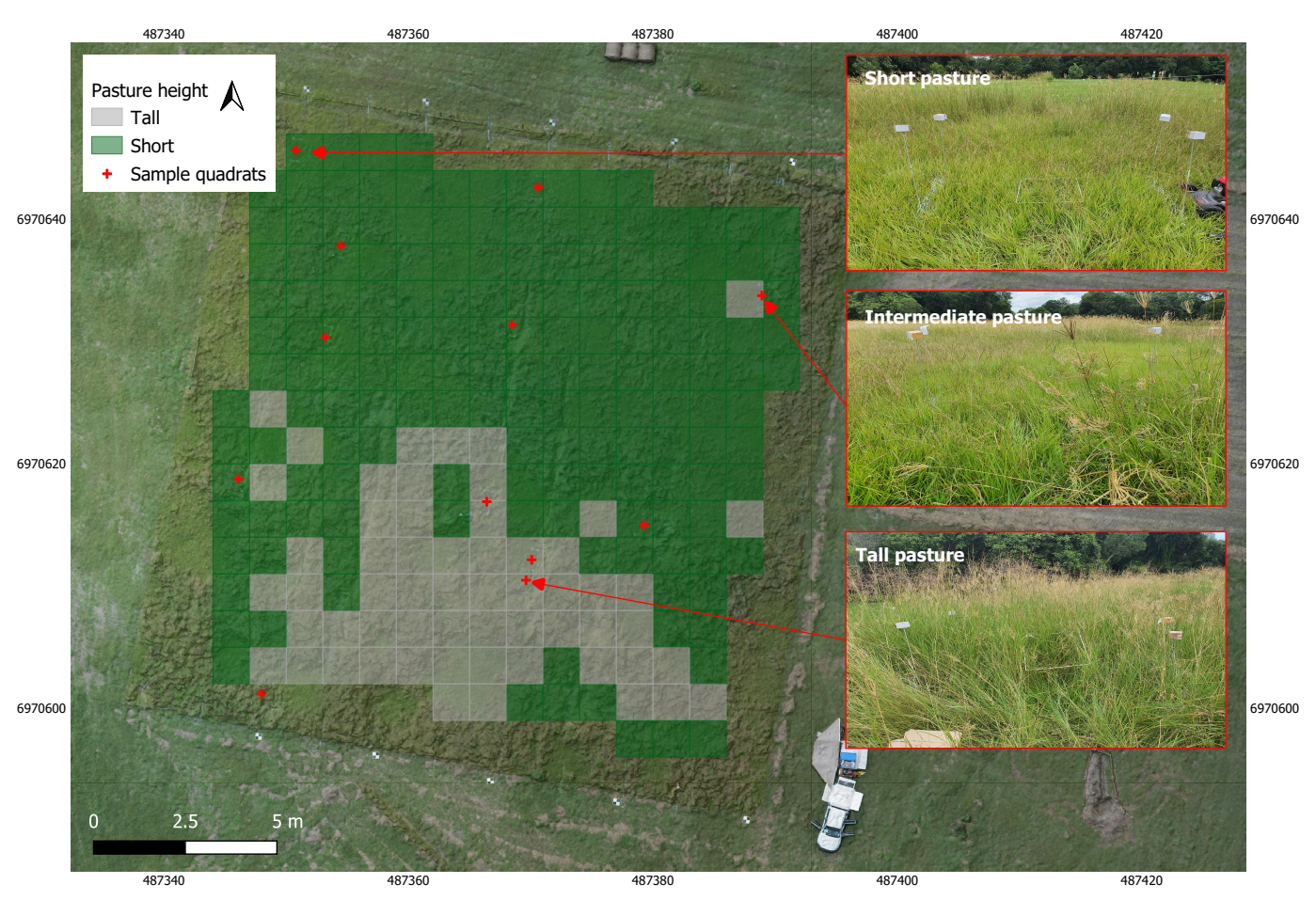

(a)

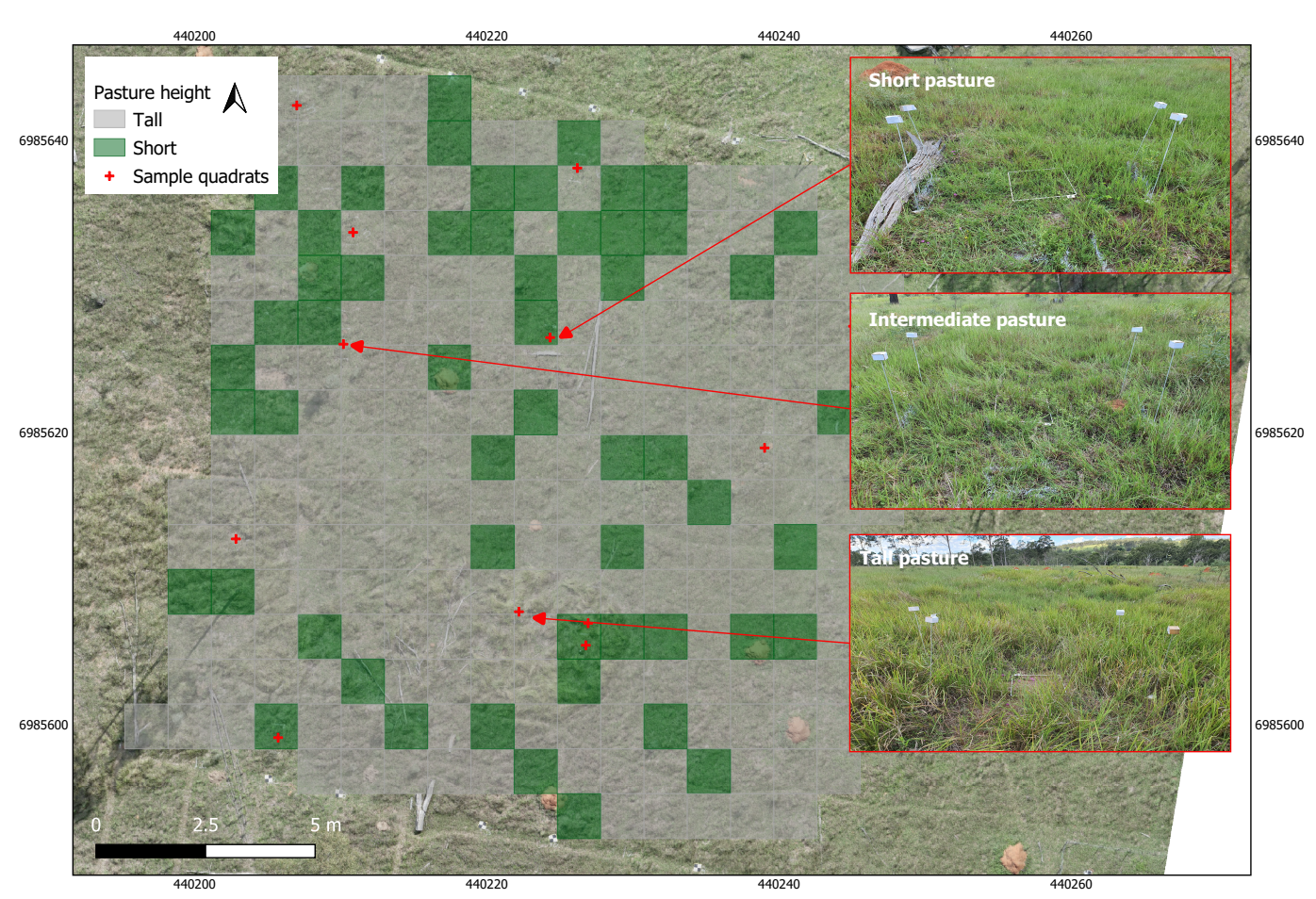

(b)

Figure 9. Planet Dove satellite image data scale map of one of the grassland (a) and woodland (b) field plots, illustrating the stratification of the pasture into tall and short forms. 
3.3.2. Planet Dove satellite image data based predictions of pasture yield

Results of the ANN modelling of both the tall and short pasture forms across both the grassland and woodland field site plots are summarised in table 5. Model mean absolute error is lowest (1.1 \& 0.9 tha $^{-1}($ TSDM $\left.)\right)$ in the case of both the tall grassland and tall woodland pasture model evaluations. The correlation between the predicted and observed estimates of pasture yield for both the grassland and woodland pastures for the tall pasture form is the weakest $\left(<0.1 R^{2}\right)$. Plots 10 and 11 for each tall and short pasture form, further illustrate both the model error and the correlation of predicted and estimated yield.

Table 5. Planet satellite pasture yield modelling summary.

\begin{tabular}{|c|c|c|c|c|c|c|c|c|c|c|c|c|}
\hline \multirow[b]{3}{*}{ Date } & \multicolumn{6}{|c|}{ Short Pasture Model } & \multicolumn{6}{|c|}{ Tall Pasture Model } \\
\hline & \multicolumn{3}{|c|}{ Calibration } & \multicolumn{3}{|c|}{ Validation } & \multicolumn{3}{|c|}{ Calibration } & \multicolumn{3}{|c|}{ Validation } \\
\hline & $N^{*}$ & $R^{2}$ & $\operatorname{MAE}^{* *}(\mathrm{t} / \mathrm{ha})$ & $N^{*}$ & $R^{2}$ & $\operatorname{MAE}^{* *}(\mathrm{t} / \mathrm{ha})$ & $N^{*}$ & $R^{2}$ & $\operatorname{MAE}^{* *}(\mathrm{t} / \mathrm{ha})$ & $N^{*}$ & $R^{2}$ & $\operatorname{MAE}^{* *}(\mathrm{t} / \mathrm{ha})$ \\
\hline $\begin{array}{l}\text { Grassland } \\
\text { March } 2021 \\
\text { Woodland }\end{array}$ & 69 & 0.7 & 1.29 & 30 & 0.6 & 1.8 & 255 & 0.2 & 1.2 & 109 & $<0.1$ & 1.1 \\
\hline Feb-March 2021 & 43 & 0.7 & 1.1 & 19 & 0.7 & 1.3 & 646 & $<0.1$ & 0.7 & 277 & $<0.1$ & 0.9 \\
\hline
\end{tabular}




\section{Calibration}

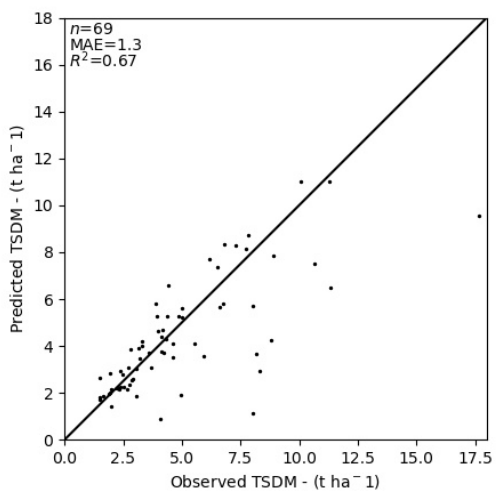

(a)

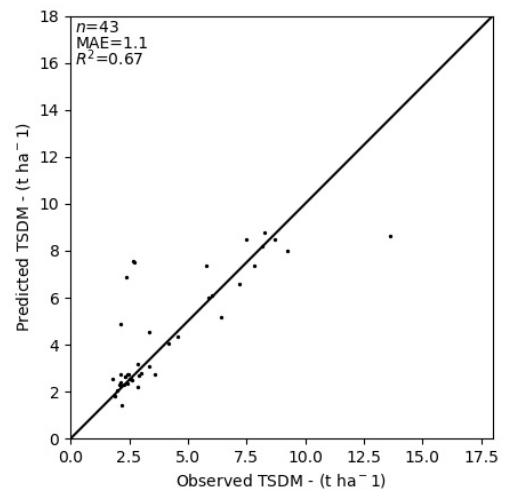

(c)
Validation

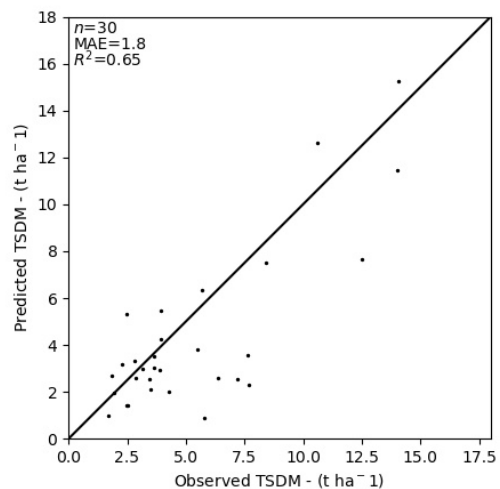

(b)

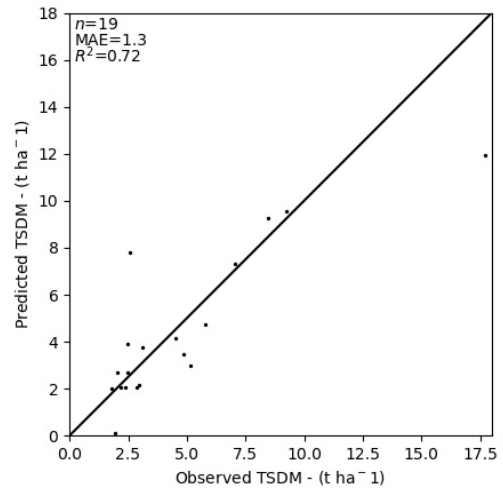

(d)

Figure 10. Least squares linear relationship between RPAS estimated biomass and Planet Dove satellite image data predicted biomass at peak growth for both the short grassland ( $\&$ b) and short woodland (c \& d) pasture models. 


\section{Calibration}

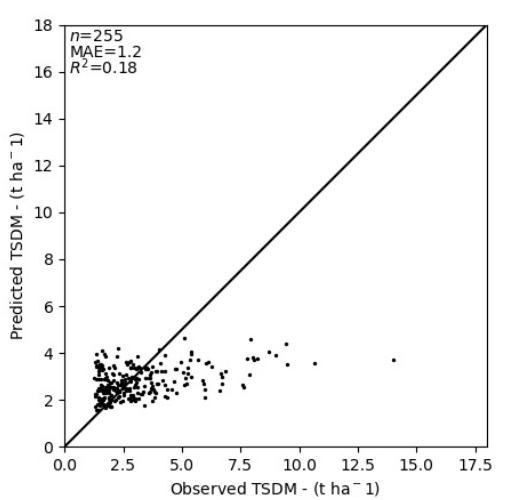

(a)

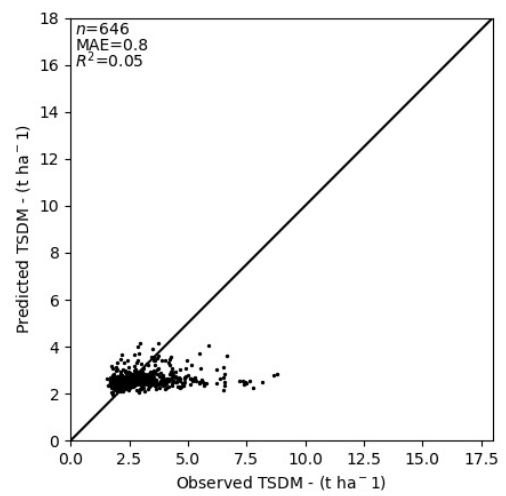

(c)
Validation

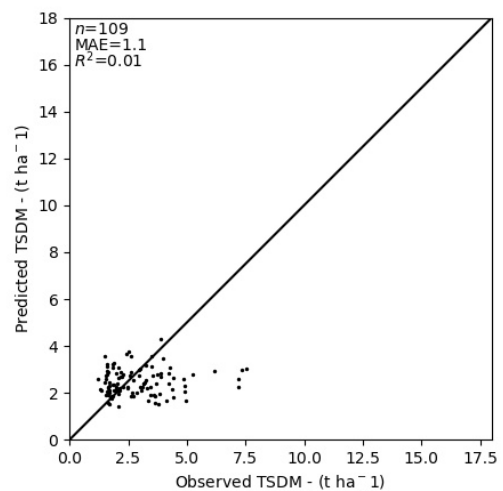

(b)

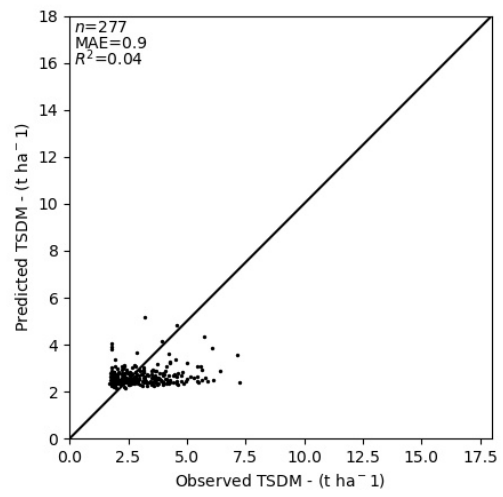

(d)

Figure 11. Least squares linear relationship between RPAS estimated biomass and Planet Dove satellite image data predicted biomass at peak growth for both the tall grassland (a \& b) and tall woodland (c \& d) pasture models. 


\section{Discussion}

The evaluation of the photogrammetric SfM derived measures of pasture height involved a simple linear least-squares correlation of each measure with the same from a terrestrial laser scan. Although this was considered a comparison with a benchmark type measurement, with the TLS measurement considered as the point of reference, a number of limitations and differences exist in making such comparisons. Spatial scale differences between the two methods exist and although the TLS measurement can be re-scaled to match a similar resolution of the SfM derived measure, of which was tested to exhibit no significant improvements, further differences exist. The perspectives of the sensing methods is the main difference. The horizontal scanning perspective of the TLS will result in occlusion of the horizontally obscured parts of the pasture sward. Penetration into the pasture sward by the TLS laser pulse is highest the closer the instrument is to the sward, and with enough overlapping and differing scan positions, adequate penetration could be achieved to fully represent the overall pasture sward. The scanning density required to achieve this remains unknown and a limitation of the comparison. It should also be noted, that the vertical perspective of the RPAS capture and SfM derived point cloud provides a general surface height representation of the pasture sward. This also obscures parts of the pasture sward. In the review of the least-squares correlation of the three pasture height metrics, the minimum height metric was most similar between methods, this was interpreted as the closest match between SfM and TLS height metrics. For example, this is likely excluding the very top components of the pasture sward, such as the pasture flower inflorescence and emergent leaves, that are resolved in the finer scale TLS point cloud but not in the SfM cloud.

The SfM plant pasture height metrics were next used, along with field measurements of pasture yield, to further predict pasture yield across each field plot. A total of approximately 100 field measurements were used in the modelling across a range of pasture heights and yields. The ANN modelling predicted yield with an adequate degree of accuracy, 0.8 TSDM $\left(t h a^{-1}\right)$ in the calibration and 1.4 TSDM $\left(t h a^{-1}\right)$ in the validation, and agreement with observed yield, $0.72 R^{2}$ in the calibration and $0.27 R^{2}$ in the validation. Some degree of over-prediction was present in the model validation. Sources of such error are potentially as a result of variability in the form and structure of the pasture sward, not adequately represented in the model calibration, across both grassland and woodland pastures. This could include the prostrate nature of the pasture in the grassland and the mixture of both tussock and prostrate forms in the woodland pasture, that require further sample representation. Application of the field quadrat scale modelling across each field site at a number of dates throughout the growing season, illustrated in figure 6, demonstrates the application of the modelling. This provides a means of both a standalone estimate of pasture yield across a field plot for further scaling to the satellite platform, as well as potentially paddock or property scale mapping of pasture yield. The methods developed here apply to the half to one-hectare field plot scale, however with further research and testing, could be applied to RPAS that have the capability to fly larger areas with similar or lower image resolution and overlapping image parameters.

The use of the RPAS estimates of pasture yield were next used to assess the ability to accurately predict yield at the satellite scale. The ability to predict yield at this scale has a number of challenges and the first is in the ability to efficiently and accurately collect sufficient amounts of training and evaluation estimates of yield. This has to a degree, through this research and others, proved successful. The next significant challenge involves the satellite-derived metrics used to predict pasture yield and the relationship these metrics exhibit with pasture yield, or more specifically, the RPAS estimates of pasture yield. The calculation of a time-series metric of plant pasture vegetation response and its persistence throughout a growing period was used as a proxy for pasture yield accumulation. This was assessed against the RPAS estimates of pasture yield and indicated a similar pattern to previous studies, in that a saturation of the satellite vegetation response and its estimated measure of persistence was seen. Further stratification of the comparison was undertaken in an effort to separate the forms of the pasture sward into those with a higher overall persistence and those with a lower. This was 
observed in the imagery to group the sward into tall or tussock forming pastures and a shorter more prostrate form.

The satellite-based prediction of pasture yield were next estimated at both pasture sward forms and at the two pasture types. Results of the ANN based modelling showed a model error of 1.1 to 1.8 TSDM $\left(t h a^{-1}\right)$ across both pasture types for the short pasture form, with a high degree of agreement between the observed and predicted $\left(0.65\right.$ to $\left.0.72 R^{2}\right)$. This was however the less abundant form of the pasture sward. The majority of the pasture was of the tall form, across both pasture types and the mean absolute error was reported between 0.8 and 1.2 TSDM $\left(t h a^{-1}\right)$, however the agreement between the predicted and observed for both pasture types was significantly poor. In both pasture types the calibration and validation was below $0.1 R^{2}$, with the exception of the tall grassland calibration that was only slightly higher at $0.18 R^{2}$. The distribution of the predicted and observed estimations is strongly skewed towards the underestimation of the pasture yield. This pattern is interpreted as a saturation of the satellite vegetation response, whereby the observed yield increases however the predicted does not. This is well documented in the literature and the result of common vegetation indices including NDVI reaching peak sensitivity. Although a number of additional indices were utilised in this study that was reported to be less effected, the nature of the pastures in this study are that of a high vegetative response and are likely still saturating. The use of the ANN modelling approach was reported by others[6] to be useful in overcoming such limitations, however it has in this study proven not to be as successful. Although the use of further spectral bands that are less sensitive to vegetation signal saturation, such as those in the short-wave infrared portion of the light spectrum, have their own unique limitations, in that they are on-board satellites with a less frequent return visit schedule, that may not provide adequate cloud free imagery throughout the peak growing period of the pasture growth cycle in areas of high rainfall. Such limitations should be the source of further research that investigates the potential of a blending or fusing of both satellite and RPAS derived imagery.

\section{Conclusions and recommendations}

This study first aimed to develop and test the accuracy of an RPAS based method to acquire sub-metre high-resolution imagery for the development of a plant pasture yield model, across both a grassland and woodland pasture, at repeated intervals throughout a period of pasture growth. Utilising techniques developed previously by the authors [4], the study employed photogrammetric structure from motion methods to map pasture height, and with coincidental repeated manual pasture yield sampling, further developed a pasture height machine learning model of pasture yield at monthly intervals throughout the growing season. An evaluation of the accuracy of the RPAS pasture height measurements with that of TLS pasture height measurement revealed agreement between both measurements. Both methods build upon previous research by [34] as an alternative rapid non-destructive and accurate method to measure plant pasture height for use in further pasture yield modelling. Recommendations for further research include investigation of optimal TLS scan configuration for further RPAS SfM pasture height evaluation. The pasture height metrics were next used, along with field measurements of pasture yield, to further predict pasture yield across each field plot. The ANN modelling predicted yield with an adequate degree of accuracy and builds upon the previous research of the authors and others [4-6]. It can be concluded that although a degree of over-prediction of pasture yield exists in the ANN modelling of yield from SfM pasture height measures, an overall estimation of yield across both space and time has been achieved with the ANN RPAS modelling approach. Further sampling across a broader range of pasture swards, across varying stages of growth, will improve the model accuracy. As a standalone method of estimating pasture yield at the field site scale, further research should investigate the potential of both, the ability to acquire imagery across larger areas with other types of RPAS at similar image quality and SfM flight overlap requirements, as well as investigate the potential to acquire lower specification RPAS imagery, to assess its impacts on pasture yield estimation accuracy. 
Next, the study aimed to further test the ability to utilise the RPAS pasture yield estimates at each growth stage to both train and evaluate a satellite derived deep-learning ANN model of pasture yield. Planet Dove satellite image data measures were regressed with each RPAS modelled estimate of yield and the ANN model calibrated and evaluated for both tall and short pasture forms. The ANN modelling predicted yield with an adequate degree of accuracy across the short pasture form, however significantly underestimated yield in the tall pastures. Saturation of the satellite vegetation response was considered the likely cause of the poor performance. Research by others including [6] concluded similar problems in the dairy pastures of Tasmania Australia, however reported improved results through the use of ANN modelling and integration of climate observations into the modelling. To the author's knowledge, this is the first time these techniques have been applied to the plant pastures of the study area, providing an important first step for further research. A number of limitations in the performance of optical-based satellite remote sensing systems to predict pasture yield, at spatial and temporal scales useful for pasture management, in high rainfall environments, exist. Further research, should investigate the integration of short-wave infrared (SWIR) satellite imagery bands into the ANN modelling. This may improve the sensitivity of the pasture photosynthetic response and reduce the apparent under-prediction in the model performance. Solar Induced Fluorescence (SIF) based measures of plant pasture photosynthesis from both RPAS and satellite imagery should also be investigated as potential ANN model pasture yield inputs. However, the limitations that coarser spatial and temporal satellite imagery will need to be considered.

The estimation of plant pasture yield from both airborne and space-borne remote sensing platforms that utilise modern machine-learning techniques, including the deep-learning neural networks used in this study, shows potential to overcome some of these limitations. It is only in the last two decades that both sensing and modelling technologies have become available, accessible, and mature. Improved pasture management in an increasingly variable climate is needed. Improved estimates of yield that can be delivered at time-critical stocking rate decision points, will become increasingly important for both profitability and long-term resilient grazing practice change. Adoption of these technologies needs to be rapid and further research is needed to improve their performance and build confidence in their use by graziers.

Author Contributions: J.B. conducted the research and wrote the paper. S.P. and P.S. provided support, advice and supervision as $\mathrm{PhD}$ advisors of the primary author. All authors have read and agreed to the published version of the manuscript.

Funding: This research received no external funding.

Acknowledgments: The anonymous reviewers for their review and feedback of the manuscript. The Jess family and staff of the Esk pastoral property that kindly provided support and access to their property. The Queensland University of Technology for access to the Samford Ecological Research Facility, in particular staff Bek Christensen and Marcus Yates for their on-site support and management. Support from the Australian Government Research Training Program Scholarship. Support and funding from the University of Queensland Joint Remote Sensing Research Program. Support and funding from the QLD Department of Environment and Science and the Department of Agriculture and Fisheries-Drought and Climate Adaptation Program, staff at the Eco-sciences Precinct Remote Sensing Centre for assistance, support, training, and advice including: Ken Brook, Christina Jones, Jacqui Willcocks and assistance in collecting and management of field data from Rebecca Farrell, Al Healy, Mathew Pringle, Skye Byer, Patrick Halloway, Tom Franz, Deanna Vandenberg, Jane Bryden-Brown, Leo Hardtke and Grant Fraser.

Conflicts of Interest: The authors declare no conflict of interest.

1. Johnston, P.; McKeon, G.; Buxton, R.; Cobon, D.; Day, K.; Hall, W.; Scanlan, J. Managing Climatic Variability in Queensland's Grazing Lands - New Approaches; 2010; chapter III, pp. 197-226.

2. Department of Agriculture and Fisheries. Queensland agriculture snapshot. https: / / www.publications.qld.gov.au / dataset/state-of-queensland-agriculture-report-june-2014/resource / 1c4ac429-da34-464d-845c-f3ad536588f8, 2018. 
3. McKeon, G.M.; Day, K.A.; Howden, S.M.; Mott, J.J.; Orr, D.M.; Scattini, W.J.; Weston, E.J. Northern Australian Savannas: Management for Pastoral Production. Journal of Biogeography 1990, 17, 355-372.

4. Barnetson, J.; Phinn, S.; Scarth, P. Estimating Plant Pasture Biomass and Quality from UAV Imaging across Queensland's Rangelands. AgriEngineering 2020, 2, 523-543. doi:10.3390/agriengineering2040035.

5. Liu, H.; Dahlgren, R.; Larsen, R.; Devine, S.; Roche, L.; O’ Geen, A.; Wong, A.; Covello, S.; Jin, Y. Estimating Rangeland Forage Production Using Remote Sensing Data from a Small Unmanned Aerial System (sUAS) and PlanetScope Satellite. Remote Sensing 2019, 11, 595. doi:10.3390/rs11050595.

6. Chen, Y.; Guerschman, J.; Shendryk, Y.; Henry, D.; Harrison, M.T. Estimating Pasture Biomass Using Sentinel-2 Imagery and Machine Learning. Remote Sensing 2021, 13. doi:10.3390/rs13040603.

7. Liu, H.; Dahlgren, R.A.; Larsen, R.E.; Devine, S.M.; Roche, L.M.; O' Geen, A.T.; Wong, A.J.; Covello, S.; Jin, Y. Estimating Rangeland Forage Production Using Remote Sensing Data from a Small Unmanned Aerial System (sUAS) and PlanetScope Satellite. Remote Sensing 2019, 11. doi:10.3390/rs11050595.

8. Noormets, A. Phenology of ecosystem processes: Applications in global change research. Phenology of Ecosystem Processes: Applications in Global Change Research 2009, pp. 1-275. doi:10.1007/978-1-4419-0026-5.

9. John, R.; Chen, J.; Noormets, A.; Xiao, X.; Xu, J.; Lu, N.; Chen, S. Modelling gross primary production in semi-arid Inner Mongolia using MODIS imagery and eddy covariance data. International Journal of Remote Sensing 2013, 34, 2829-2857. doi:10.1080/01431161.2012.746483.

10. Gómez-Giráldez, P.J.; Pérez-Palazón, M.J.; Polo, M.J.; González-Dugo, M.P. Monitoring grass phenology and hydrological dynamics of an oak-grass savanna ecosystem using sentinel-2 and terrestrial photography. Remote Sensing 2020, 12. doi:10.3390/rs12040600.

11. Ma, X.; Huete, A.; Yu, Q.; Restrepo-Coupe, N.; Beringer, J.; Hutley, L.B.; Kanniah, K.D.; Cleverly, J.; Eamus, D. Parameterization of an ecosystem light-use-efficiency model for predicting savanna GPP using MODIS EVI. Remote Sensing of Environment 2014, 154, 253-271. doi:10.1016/j.rse.2014.08.025.

12. Yuan, W.; Cai, W.; Xia, J.; Chen, J.; Liu, S.; Dong, W.; Merbold, L.; Law, B.; Arain, A.; Beringer, J.; Bernhofer, C.; Black, A.; Blanken, P.D.; Cescatti, A.; Chen, Y.; Francois, L.; Gianelle, D.; Janssens, I.A.; Jung, M.; Kato, T.; Kiely, G.; Liu, D.; Marcolla, B.; Montagnani, L.; Raschi, A.; Roupsard, O.; Varlagin, A.; Wohlfahrt, G. Global comparison of light use efficiency models for simulating terrestrial vegetation gross primary production based on the LaThuile database. Agricultural and Forest Meteorology 2014, 192-193, 108-120. doi:10.1016/j.agrformet.2014.03.007.

13. Wei, S.; Yi, C.; Fang, W.; Hendrey, G. A global study of GPP focusing on light-use efficiency in a random forest regression model. Ecosphere 2017, 8. doi:10.1002/ecs2.1724.

14. Gitelson, A.A.; Gamon, J.A. The need for a common basis for defining light-use efficiency: Implications for productivity estimation. Remote Sensing of Environment 2015, 156, 196-201. doi:10.1016/j.rse.2014.09.017.

15. Monteith, J. SOLAR RADIATION AND PRODUCTIVITY IN TROPICAL ECOSYSTEMS. Journal of Applied Ecology 1972, 9, 747.

16. Sibanda, M.; Mutanga, O.; Rouget, M. Examining the potential of Sentinel-2 MSI spectral resolution in quantifying above ground biomass across different fertilizer treatments. ISPRS Journal of Photogrammetry and Remote Sensing 2015, 110, 55-65. doi:https:/ / doi.org/10.1016/j.isprsjprs.2015.10.005.

17. Filho, M.G.; Kuplich, T.M.; Quadros, F.L.F.D. Estimating natural grassland biomass by vegetation indices using Sentinel 2 remote sensing data. International Journal of Remote Sensing 2020, 41, 2861-2876, [https:/ / doi.org/10.1080/01431161.2019.1697004]. doi:10.1080/01431161.2019.1697004.

18. Bretas, I.L.; Valente, D.S.; Silva, F.F.; Chizzotti, M.L.; Paulino, M.F.; D’Áurea, A.P.; Paciullo, D.S.; Pedreira, B.C.; Chizzotti, F.H. Prediction of aboveground biomass and dry-matter content in brachiaria pastures by combining meteorological data and satellite imagery. Grass and Forage Science 2021. doi:10.1111/gfs.12517.

19. PlanetLabs. Surface Reflectance Technical White Paper. Technical report, 2018.

20. Jansen, V.S.; Kolden, C.A.; Schmalz, H.J.; Karl, J.W.; Taylor, R.V. Using Satellite-Based Vegetation Data for Short-Term Grazing Monitoring to Inform Adaptive Management. Rangeland Ecology and Management 2021, 76, 30-42. doi:10.1016/j.rama.2021.01.006.

21. Clementini, C.; Pomente, A.; Latini, D.; Kanamaru, H.; Vuolo, M.R.; Heureux, A.; Fujisawa, M.; Schiavon, G.; Frate, F.D. Long-term grass biomass estimation of pastures from satellite data. Remote Sensing 2020, 12,1-41. doi:10.3390/rs12132160.

22. Chollet, F. Deep Learning with Python; Manning, 2017.

23. Bureau of Meteorology. Climate Data Online. http://www.bom.gov.au/climate/data/, 2020. 
24. Pix4D. Pix4Dmapper software program. https://www.pix4d.com/, 2020.

25. Planetlabs. PLANET IMAGERY PRODUCT SPECIFICATION: PLANETSCOPE \& RAPIDEYE. Technical report, 2016.

26. Contributors, P. PDAL Point Data Abstraction Library, 2018. doi:10.5281/zenodo.2556738.

27. Zhang, K.; Chen, S.C.; Whitman, D.; Shyu, M.L.; Yan, J.; Zhang, C. A progressive morphological filter for removing nonground measurements from airborne LIDAR data. Geoscience and Remote Sensing, IEEE Transactions on 2003, 41, 872 - 882. doi:10.1109/TGRS.2003.810682.

28. Abadi, M.; Agarwal, A.; Barham, P.; Brevdo, E.; Chen, Z.; Citro, C.; Corrado, G.S.; Davis, A.; Dean, J.; Devin, M.; Ghemawat, S.; Goodfellow, I.; Harp, A.; Irving, G.; Isard, M.; Jia, Y.; Jozefowicz, R.; Kaiser, L.; Kudlur, M.; Levenberg, J.; Mané, D.; Monga, R.; Moore, S.; Murray, D.; Olah, C.; Schuster, M.; Shlens, J.; Steiner, B.; Sutskever, I.; Talwar, K.; Tucker, P.; Vanhoucke, V.; Vasudevan, V.; Viégas, F.; Vinyals, O.; Warden, P.; Wattenberg, M.; Wicke, M.; Yu, Y.; Zheng, X. TensorFlow: Large-Scale Machine Learning on Heterogeneous Systems, 2015. Software available from tensorflow.org.

29. Sadeh, Y.; Zhu, X.; Dunkerley, D.; Walker, J.P.; Zhang, Y.; Rozenstein, O.; Manivasagam, V.S.; Chenu, K. Fusion of Sentinel-2 and PlanetScope time-series data into daily $3 \mathrm{~m}$ surface reflectance and wheat LAI monitoring. International Journal of Applied Earth Observation and Geoinformation 2021, 96, 102260. doi:https:/ /doi.org/10.1016/j.jag.2020.102260.

30. Haboudane, D.; Miller, J.R.; Pattey, E.; Zarco-Tejada, P.J.; Strachan, I.B. Hyperspectral vegetation indices and novel algorithms for predicting green LAI of crop canopies: Modeling and validation in the context of precision agriculture. Remote Sensing of Environment 2004, 90, 337-352. doi:https:/ / doi.org/10.1016/j.rse.2003.12.013.

31. Rouse, J.; Haas, R.H.; Schell, J.A.; Deering, D. Monitoring vegetation systems in the great plains with ERTS. 1973.

32. Roujean, J.L.; Breon, F.M. Estimating PAR absorbed by vegetation from bidirectional reflectance measurements. Remote Sensing of Environment 1995, 51, 375-384. doi:https:/ / doi.org/10.1016/0034-4257(94)00114-3.

33. Barnetson, J.; Phinn, S.; Scarth, P.; Denham, R. Assessing Landsat Fractional Ground-cover Time Series across Australia's Arid Rangelands: Separating Grazing Impacts from Climate Variability. The International Archives of the Photogrammetry, Remote Sensing and Spatial Information Sciences 2017, XLII-3/W2, 15-26. doi:10.5194/isprs-archives-XLII-3-W2-15-2017.

34. Cooper, S.; Roy, D.; Schaaf, C.; Paynter, I. Examination of the Potential of Terrestrial Laser Scanning and Structure-from-Motion Photogrammetry for Rapid Nondestructive Field Measurement of Grass Biomass. Remote Sensing 2017, 9.

Publisher's Note: MDPI stays neutral with regard to jurisdictional claims in published maps and institutional affiliations. 